\title{
Pruritic Dermatoses: Overview of Etiology and Therapy
}

\author{
Ernest N. Charlesworth, MD, Vincent S. Beltrani, Sr., MD
}

This review begins with a brief survey of the neurophysiology and neuroanatomy of pruritus, and goes on to describe the etiology of the major allergic and nonallergic pruritic disorders. The etiology of pruritus often suggests the appropriate treatment. For example, urticaria, which is primarily mediated by histamine, is amenable to treatment with $\mathrm{H}_{1}$ antihistamines. Second-generation, nonsedating antihistamines appear to be more effective than sedating antihistamines, perhaps because of better compliance. Other systemic pharmacologic options may be useful in nonhistamine-mediated disorders, for example, immunomodulators for inflammation-induced pruritus or opiate antagonists for atopic dermatitis. Nonpharmacologic measures, such as proper skin care, and physical modalities, such as phototherapy or acupuncture, may also be helpful. Am J Med. 2002;113(9A):25S-33S. (C) 2002 by Excerpta Medica, Inc.
$\mathrm{T}$ The skin reacts to physical and inflammatory stimuli in only a limited number of ways. The sensation of itching, or pruritus, is the most common symptom of dermatologic conditions. In 1660, the German physician Samuel Hafenreffer defined itching as an "unpleasant sensation that provokes the desire to scratch," and although this definition has been modified to correlate with current knowledge, it remains a reasonable one. ${ }^{1}$ Pruritus is the subjective sensation of itching. The types and causes are complex and not yet completely understood. Perhaps the unfortunate plight of the itching patient is best described in this brief poem by Julian Verbov $^{2}$ :

\footnotetext{
I itch, I itch, the whole day through I also itch at night.

I try so hard to stop myself

I'm looking such a sight.
To itch is not so nice you know, It really is deplorable
But to scratch is really something
That is often quite enjoyable.

The sensation of itch is the common factor in a multitude of diverse cutaneous disorders. Histamine is the primary mediator of itching in some types of allergic disease, but multiple agents or mediators can provoke itching in both allergic and nonallergic diseases.

This review provides a brief overview of the pathogenesis of itching, describes the major itching skin disorders related to allergic and nonallergic disease, and includes a discussion of nonpharmacologic and pharmacologic therapies.

\section{WHAT CAUSES PRURITUS?}

Diffuse itch is believed to be induced by specific, nonmyelinated C-fiber stimulation, whereas itch that is localized both in space and time involves the A- $\delta$ fibers. ${ }^{3} \mathrm{~A}$ complex plexus of nonmyelinated, dendritic processes are believed to be present at the distal endings of these fibers, which terminate in the lower epidermis and possibly at the dermal-epidermal junction, where the "itch receptors," not yet morphologically identified, are presumed to be located. These polymodal (responsive to mechanical, thermal, and chemical stimuli) nociceptors are found only in the skin, mucus membranes, and cornea. ${ }^{4}$ No other tissue experiences pruritus. It is now generally accepted that the sensations of itch and pain are transmitted
From the Department of Allergy and Dermatology, Shannon Clinic, San Angelo, Texas, and Department of Allergy and Clinical Immunology, University of Texas Medical School at Houston, Houston, Texas, USA (ENC); and the Department of Dermatology, College of Physicians and Surgeons, Columbia University School of Medicine, New York, New York, USA (VSB).

Requests for reprints should be addressed to Ernest N. Charlesworth, MD, Shannon Clinic, Department of Dermatology and Allergy, 215 East College Avenue, San Angelo, Texas 76903. E-mail: echarlesworth@ shannonhealth.org. 


\section{NEURAL PATHWAYS}

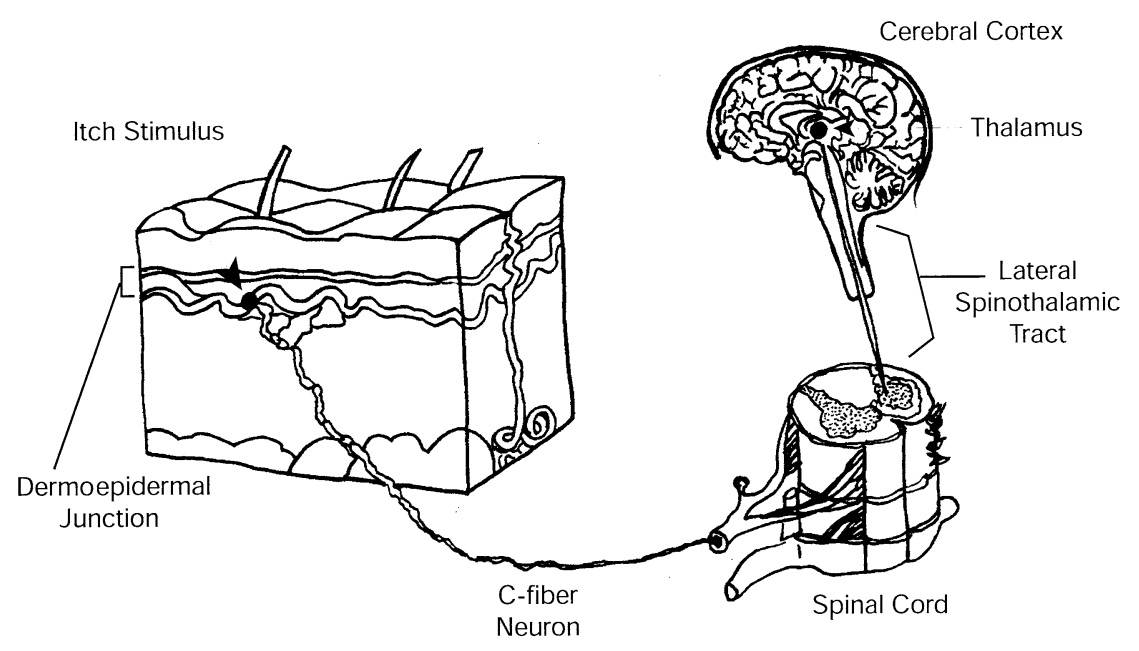

Figure 1. Simplified diagram of the neuroanatomic pathways for pruritus. Dendritic itch receptors in the epidermis and dermoepidermal junction can be activated by (proinflammatory) pruritogenic mediators, which travel through the peripheral sensory nonmyelinated C-fibers to the dorsal root ganglia to the dorsal roots and into the spinal cord. The spinothalamic relay axons cross to the contralateral ventrolateral quadrant rostral to the level at which the sensory neurons enter the spinal cord. The C-fibers reach the thalamus and hypothalamus by means of the reticular formation of the encephalic trunk to the cerebral cortex.

by separate C-fibers. The magnitude of itch can be modulated by changes in stimulus frequency, but the quality of itch does not change into pain at high frequencies. ${ }^{5}$ Both $\mathrm{C}-$ and $\mathrm{A}-\delta$ fibers conduct impulses at varying speeds to the spinal cord by means of the dorsal nerve roots of the spinal nerves. Figure 1 provides a simplified illustration of the pathway of itch sensations mediated by C-fibers.

Although the peripheral and central mechanisms of itch are not fully understood, both altered peripheral excitation and central disinhibition are involved. Local paroxysmal pruritus is believed to have a central origin. Central inhibition may be partially restored by scratching. This phenomenon is the basis of the "gate-control" theory, which suggests that scratching and vibration cause neural impulses to travel on the larger A-fibers, inhibiting the itch signals in the slower C-fibers. ${ }^{6}$ The A-fiber input "closes the gate" to the C-fiber output. ${ }^{7}$ Endogenous enkephalins are also believed to act at the spinal level to modulate the perception of itch. Scratching may abolish itch by central inhibition rather than by fatigue of the peripheral sensory receptor.

\section{ENDOGENOUS AGENTS THAT CAUSE PRURITUS}

Although numerous substances are thought to cause pruritus, ${ }^{8}$ direct evidence exists only for a causal role of histamine in the itching experienced by patients with urticaria or mastocytosis. Other agents that have been investigated in pruritus include serotonin, prostaglandins, proteases, kinases, cytokines, leukotrienes, neuropeptides, leukotrienes, opioids, and endorphins.

\section{Histamine}

Injection of histamine results in the characteristic symptoms of acute urticaria: the "triple response" of Lewis dissipating within 1 hour. Urticaria and pruritus that last $>1$ hour are unlikely to be caused solely by histamine, and the typical triple response is never noted in other pruritic dermatoses. Histamine generates itch through activation of $\mathrm{H}_{1}$, but not $\mathrm{H}_{2}$, itch receptors. ${ }^{9}$ It is also believed to render the zone of surrounding skin abnormally sensitive to other stimuli. Stimuli normally perceived as tactile, pressure, or temperature-change sensations are instead perceived as itch, in a phenomenon known as alloknesis. ${ }^{10}$

\section{Serotonin and the Prostaglandins}

Other chemical mediators of pruritus include serotonin, which is weakly pruritogenic and inconsistently produces a painful itch when injected intradermally, ${ }^{11}$ and the prostaglandins ( $\mathrm{PGE}_{1}, \mathrm{PGE}_{2}$, endoperoxidases), which are weak pruritogens by themselves, but which can markedly increase the itch response when given with serotonin or with histamine. ${ }^{12,13}$

\section{Proteinases and Kinins}

These substances have also been proposed as mediators of itch. The injection of trypsin or chymotrypsin produces intense itch associated with the triple response of Lewis, an effect that is inhibited by antihistamines, suggesting that histamine is the primary mediator. Administration 
of papain or kallikrein causes a painful pricking sensation that is not associated with the triple response and does not respond to antihistamines. ${ }^{14}$ However, if proteinases are mediators of pruritus, they probably function by damaging nerve terminals, which results in stimulation of itch fibers, rather than by inducing release of chemical mediators of pruritus. ${ }^{15}$

\section{Cytokines}

This family of agents, considered to constitute "histamine-releasing factor," have been proposed as mediators of histamine-independent itching. However, except for interleukin (IL)-2, which shows a rapid, mild pruritogenic effect, ${ }^{16}$ none has been shown to either induce or prevent pruritus. Interestingly, although the level of tumor necrosis factor (TNF) $-\alpha$ is elevated in many pruritic dermatoses, it does not induce pruritus when injected into the skin.

\section{Leukotrienes}

These agents, which are end products of arachidonic acid metabolism, evoke inflammation, but not pruritus, when injected intracutaneously. ${ }^{17}$ Although antileukotriene therapy is virtually useless for treating pruritus, there are several reports of some decrease in the itch of Sjögren syndrome with the use of zileuton, a 5-lipoxygenase inhibitor, which suppresses the release of leukotrienes B4, $\mathrm{C} 4, \mathrm{D} 4$, and $\mathrm{E} 4 .^{18}$

\section{NEUROPEPTIDES}

Such agents as substance $P$, vasoactive intestinal polypeptide, and neurotensin A are abundant in the sensory neurons of the skin. Substance P and vasoactive intestinal polypeptide are the most potent histamine-liberating agents in humans. ${ }^{11}$ Substance P induces the triple response, suggesting that its effects are probably mediated by histamine, which would be consistent with the observation that the pruritic effects of substance $P$ can be blocked by oral antihistamines. However, none of the peptides are directly pruritogenic, and it remains to be determined whether neuropeptides are responsible for clinical pruritus.

\section{Opioids and Endorphins}

The role of these agents in the production of itch is unclear. Pruritus is the most common side effect of the intrathecal administration of opioids. Opioids can stimulate $\kappa$ - and $\delta$-receptors in the central nervous system ${ }^{19}$ and induce the release of histamine and other preformed mediators from mast cells. ${ }^{20}$ Interestingly, the various opioids differ in their capacity to release histamine, which suggests that the mechanism is not immunologic. ${ }^{21}$ In the pruritic dermatoses, opioids and endorphins have not been conclusively implicated in the production of itch. However, opioid antagonists, such as naloxone, naltrexone, ondansetron, and rifampicin, effectively control
Table 1. Allergic and Nonallergic Causes of Pruritus

\begin{tabular}{l} 
- Allergic \\
-Atopic dermatitis \\
-Urticaria \\
- Nonallergic \\
-Endocrine diseases \\
Hyperthyroidism \\
Hypothyroidism \\
Hyperparathyroidism \\
Hyperphosphatemia \\
Diabetes mellitus \\
—Metabolic diseases \\
Chronic renal failure \\
Cholestasis \\
Carcinoid syndrome \\
—Malignant diseases \\
Lymphoma \\
Leukemia \\
Polycythemia rubra vera \\
—Autoimmune diseases \\
Dermatitis herpetiformis \\
Linear IgA syndrome \\
—Miscellaneous \\
Parasites \\
Pruritus ani and pruritus scroti/vulvi \\
Neuropsychiatric causes \\
\hline
\end{tabular}

IgA = immunoglobulin A.

opioid-induced pruritus. Evidence increasingly suggests that endogenous opioids (endorphins) may be involved in transmission of itch. ${ }^{22}$

\section{ALLERGIC PRURITUS}

Atopic dermatitis $(\mathrm{AD})$ and urticaria are allergic diseases in which pruritus is a predominant symptom. A multitude of nonallergic causes for pruritus also exist (Table 1).

\section{Atopic Dermatitis}

$\mathrm{AD}$ refers to the chronic, subacute, eczematous skin lesions characterized by an unrelenting itch. AD is generally defined as a chronically relapsing inflammatory skin disease that frequently occurs in patients with a personal or family history of asthma or allergic rhinitis. ${ }^{23}$ The disorder, which is increasing in frequency, has an estimated incidence of $10 \% .{ }^{23}$ In contrast to other dermatologic disorders that are characterized by a primary lesion, e.g., psoriasis (papulosquamous lesions) or dermatitis herpetiformis (DH; vesicular bullous lesions), AD lacks a primary skin lesion. Only the secondary cutaneous findings of excoriation, weeping, and lichenification, as well as pigmentary changes, are apparent. Hanifin and Rajka ${ }^{24}$ have defined the major and minor criteria for AD. Just as allergic rhinitis is characterized by sneezing and extrinsic asthma is defined by wheezing, $\mathrm{AD}$ is characterized by 
Table 2. Immune Abnormalities Present in Atopic Dermatitis

- Increased IgE synthesis

- Increased immediate skin-test reactivity to allergens

- Increased basophil histamine release

- Impaired delayed-type hypersensitivity response

- Decreased CD8 suppressor/cytotoxic number and function

- Increased sIL-2 receptor levels

- Increased expression of CD23 on mononuclear cells

- Increased production of IL-4 and IL-5

- Decreased production of IFN- $\gamma$

$\mathrm{CD}=$ cluster of differentiation; IFN = interferon; IgE = immunoglobulin E; IL = interleukin; sIL = soluble interleukin.

itching. ${ }^{25}$ Therefore, an AD-like syndrome but without itching should lead one to consider other diagnoses. Because the onset of $\mathrm{AD}$ typically occurs at an early age, new-onset pruritic eczematous dermatitis in an elderly adult is more likely to be caused by cutaneous T-cell lymphoma or another disorder.

The itch sensation in $\mathrm{AD}$ can be produced by a number of different chemical mediators. Some of them serve as histamine liberators, although it would be naive to think that histamine is the sole or even the primary evoker of the itch in this disease. In addition to an increase in the presence of mediators that provoke itching, it is possible that such patients have a decreased "itch threshold," which may be even more important in the pathophysiology of AD than chemical mediators. The complexity of the perception of itching and the importance of the lowered itch threshold is underscored by the existence of multiple environmental factors that contribute to $A D$, including exposure to woolen clothing, perspiration, and bacterial toxins; even psychological factors have been implicated.

Immunohistochemical staining of both acute and chronic lesions of $\mathrm{AD}$ shows lymphocytic infiltrates consisting of cluster of differentiation (CD)3, CD4, and CD45RO memory T cells. Nearly all T-cell infiltrates in AD lesions express high levels of skin lymphocyte homing receptor, cutaneous lymphocyte-associated antigen. The ability of the memory $\mathrm{T}$ cells to target the skin is further enhanced by the presence of vascular cell adhesion molecule-1, which acts as a vascular adhesion ligand for eosinophils. An abundance of major basic protein has been detected in the dermis of patients with $\mathrm{AD}$, representing the "footprints" of eosinophils in this inflammatory battle. Some of the immunoregulatory abnormalities found in AD are listed in Table 2. It is clear that Th2 and Th1 cytokines contribute to the pathogenesis of the skin inflammation in $\mathrm{AD}$, but the exact pathogenesis of the itching remains unclear. The skin of patients with $\mathrm{AD}$ is inherently pruritic; in no other dermatitis is the relation between physical and emotional components interwoven so tightly. ${ }^{26}$

\section{Urticaria}

Urticaria is a common disorder of the skin characterized by the transient appearance of elevated, erythematous lesions that often have a pale center and that wax and wane, moving from one site to another. ${ }^{27,28}$ Urticaria is typically markedly pruritic. Exceptions are urticarial vasculitis and delayed-pressure urticaria, which are characterized by pain or a burning sensation. ${ }^{27}$

Histamine is the primary mediator for most types of urticaria. Kaplan et $\mathrm{al}^{29,30}$ reported that $93 \%$ of patients with chronic urticaria clearly exhibited increased histamine release into skin blisters overlying lesions of urticaria. In 4 of 5 patients with cold urticaria, levels of histamine were significantly elevated in skin blister fluid.

An additional mechanism of chronic urticaria is the production of an immunoglobulin (Ig) G autoantibody directed against the high-affinity $\alpha$-subunit of the IgE receptor on mast cells and basophils. ${ }^{31}$ This may occur in as many as $30 \%$ of patients with chronic idiopathic urticaria. Many of these patients develop a wheal and flare in response to a skin test with autologous serum, suggesting that a serum factor may induce histamine release from cutaneous mast cells. There is also evidence that the histopathologic finding in these patients may resemble those in patients with cutaneous late-phase responses to allergen, with the observation of a polymorphous infiltrate consisting of eosinophils, neutrophils, and mononuclear cells. ${ }^{32,33}$ Although classic antihistamines may show a partial therapeutic effect in these patients, a strong argument can be made for the use of newer nonsedating $\mathrm{H}_{1}$ antihistamines, which may demonstrate some anti-inflammatory effects, such as inhibition of eosinophil migration and synthesis and release of mast cell mediators, in addition to their $\mathrm{H}_{1}$-receptor actions. ${ }^{34-36}$

Urticarial vasculitis is a small-vessel vasculitis in which the morphology of the skin lesions resembles that of ordinary urticaria, whereas the histopathologic features are those of leukocytoclastic vasculitis. A skin biopsy is required to confirm the diagnosis. Clinically, the lesions tend to persist in the same general areas beyond 24 hours and may leave a purpuric stain on the skin. ${ }^{37}$ Extracutaneous symptoms may occur and are often associated with a decrease in serum complement. Musculoskeletal complaints, such as arthralgias and arthritis, occur in 50\% to $75 \%$ of patients. Gastrointestinal symptoms, including abdominal pain, nausea, vomiting, and diarrhea, occur in approximately $17 \%$ to $30 \%$ of patients. Renal or pulmonary involvement may also appear as a late complication.

Unlike the more common types of urticaria, urticarial vasculitis involves more complex mechanisms than histamine release into the skin. This explains why antihistamines, although useful for the control of pruritus in urticarial vasculitis, may not control the disease. Although histamine may play a role in the early phase of urticarial vasculitis, in later stages circulating antigen-antibody 
complexes form in the blood and are deposited in the vessel walls. Complement is activated by the classic pathway, and C3a and C5a are generated, both of which are anaphylatoxins that contribute to the clinical lesions of urticaria. These anaphylatoxins are capable of inducing skin mast cells to release histamine but also can set into motion the generation of multiple cytokines and chemokines that function as chemotactic factors, resulting in the influx of neutrophils and eosinophils. The antibody isotype in the immune complexes of urticarial vasculitis is usually IgG or IgM. The antigen may be autologous or exogenous from an infectious agent or a medication.

\section{Cutaneous Mastocytosis}

Although there is no evidence that cutaneous mastocytosis is an allergic skin disease, the systemic release of mast cell-derived histamine causes generalized itching, increased vasopermeability, bronchoconstriction, urticaria, and even gastric hypersecretion. Clinical syndromes of mastocytosis range from localized cutaneous involvement to mast cell leukemia, all of which are characterized by the excess production of mast cell mediators, with histamine being the primary culprit. ${ }^{38}$

Urticaria pigmentosa is perhaps the most common presentation of mastocytosis in both children and adults. The lesions of urticaria pigmentosa are usually erythematous brownish plaques that urticate when stroked or rubbed (Darier sign). Itching may be intense and is sometimes triggered by cutaneous trauma, friction, temperature, alcohol ingestion, and certain drugs (e.g., codeine).

\section{NONALLERGIC PRURITUS}

Patients with pruritus unrelated to allergic disease may exhibit a variety of underlying causal medical conditions, among them chronic renal disease, primary biliary cirrhosis, endocrine disorders, and malignant disease.

\section{Chronic Renal Disease}

About $50 \%$ of patients with chronic renal disease have pruritus, as do an estimated $80 \%$ of patients on chronic renal dialysis. Mechanisms include xerosis, hyperparathyroidism, iron deficiency, neuropathy, and possibly cholestasis. ${ }^{39}$ Rarely are antihistamines effective in suppressing itching in these patients, even though plasma histamine levels are elevated in uremia, and skin mast cells are increased in chronic renal disease. ${ }^{40,41}$ Treatment includes dietary restrictions and phosphate-binding therapy, as well as hydration therapy for xerosis. Although antihistamines may offer some relief, ultraviolet B or psoralen plus ultraviolet A are common treatments.

\section{Primary Biliary Cirrhosis}

Itching precedes the appearance of jaundice in $50 \%$ of patients with primary biliary cirrhosis, which occurs almost exclusively in women $>30$ years old. Although pruritus may develop in many disorders associated with bil- iary obstruction, there is little or no correlation between serum concentrations of bile salts and the actual severity of itching. However, a role of bile salts in the skin cannot be dismissed, because the application of bile salts to skin blister bases in concentrations approaching those found clinically produces intense itching. ${ }^{42}$ Recent studies suggesting that opioid peptides may play a role in the pruritus of cholestasis have generated interest in the potential of opioid antagonists, such as naloxone and naltrexone, as histamine-independent therapies for treating pruritic skin diseases. $^{43,44}$

\section{Endocrine Disorders}

Pruritus is not uncommon in endocrine disorders. Generalized itching may be a presenting symptom of thyrotoxicosis, possibly related, in part, to an increase in blood flow to the skin. Hypothyroidism may also be associated with itching, which is aggravated by the dryness of the skin typical of this condition. Although generalized pruritus is not a feature of diabetes mellitus, localized itching secondary to candidiasis is very common.

\section{Malignant Disease}

The possibility of an underlying malignant disease should be considered in the middle-aged or elderly patient who presents with generalized pruritus. An expensive workup is usually not justified, and the evaluation should be guided by a detailed history and physical examination. Lymphoma is the most likely associated neoplasm, with Hodgkin disease the most likely lymphoma. Patients with polycythemia vera report a most unusual water-induced itching that is worse on the lower extremities. ${ }^{45}$ Interestingly, such itching may precede the development of polycythemia by several years. A similar symptom has been reported in association with hypereosinophilic syndrome and myelodysplasia syndrome. ${ }^{46}$

\section{Dermatitis Herpetiformis}

DH is an intensely pruritic papular vesicular disorder associated with a gluten-sensitive enteropathy similar to that seen with celiac disease. Pruritus is the primary symptom, although some patients may experience burning. Lesions are distributed symmetrically over the extensor surfaces of the elbows, knees, and buttocks. DH is an autoimmune disorder in which serum IgA and IgG antireticulin antibodies are found in many patients. Granular deposits of IgA are seen in the papillary dermis. ${ }^{47}$ These deposits lead to activation of the alternative complement pathway, resulting in an influx of neutrophils and eosinophils, which ultimately contributes to blister formation. Persons with certain human leukocyte antigen (HLA) antigens, including HLA-B8 and HLA-DR3, appear to be predisposed to develop DH. Oral dapsone (diaminodiphenyl sulfone) or sulfapyridine relieves symptoms within a few days. 


\section{Linear IgA Dermatosis and Chronic Bullous Disease of Childhood}

Linear IgA dermatosis (LAD) and chronic bullous disease of childhood (CBDC) are heterogeneous syndromes in which patients present with annular or grouped papules, vesicles, and bullae. Like DH, the lesions of LAD and CBDC are distributed symmetrically over the extensor surfaces of the elbows, knees, and buttocks. Unlike DH, these diseases are not associated with a gluten-sensitive enteropathy. CBDC is more common in children $<5$ years, with a slight predominance in girls. Like $\mathrm{DH}$, $\mathrm{CBDC}$ and LAD are strongly associated with the presence of the HLA-B8 haplotype, and immunofluorescence of perilesional skin shows a homogeneous band of IgA along the dermal-epidermal junction. In adults with LAD, there is an association with lymphoid and nonlymphoid malignancies. Like DH, LAD responds to dapsone or sulfapyridine but not to a gluten-free diet. CBDC is usually a self-limited disease that tends to remit spontaneously within 2 years but may require treatment with dapsone or prednisone.

\section{TREATMENT OF PRURITUS}

The therapeutic objective in pruritis is its cessation. Achievement of this goal can be difficult, and treatments are as diverse as the causes (Table 3). ${ }^{48-62}$ Therapy should focus on the elimination of a definable trigger. Pruritus should always be considered as symptomatic of an underlying problem. However, too often the provocative factor is unidentifiable or not curable. Symptomatic treatment is then the only option.

Histamine-induced pruritus, which is always accompanied by a wheal and flare response, is amenable to treatment with $\mathrm{H}_{1}$ antihistamines, which effectively inhibit activation of the $\mathrm{H}_{1}$ receptors. Such agents prevent, to varying degrees, but do not reverse, the responses mediated by histamine alone. The best results are attained when the antihistamine is administered "around-theclock," not simply taken as needed. Maximum benefit often requires the administration of doses higher than those recommended. Doenicke et $\mathrm{al}^{63}$ found that currently recommended regimens do not adequately prevent the effects of histamine and suggest that additional doses after 4 hours may be needed to achieve an adequate therapeutic response. Flushing is the first symptom to respond to antihistamine therapy. Flushing syndromes show a better response when both $\mathrm{H}_{1}$ and $\mathrm{H}_{2}$ antagonists are administered.

The choice of antihistamine is based on its effectiveness, frequency of administration, and side-effect profile. The dose of the $\mathrm{H}_{1}$ antagonist should be increased to tolerance, and adding an antihistamine from another group has been shown to be more helpful than increasing the dose of a single agent. ${ }^{64}$
Table 3. Treatment of Pruritic Skin Disorders

- Identify and treat the provocative factors

- Provide patient education on proper skin care Short, cool showers or 20- to 30-minute tepid baths Limit mild soap use to intertriginous areas only Lubricate frequently, especially after bathing Humidify ambient environment (in winter)

- Avoid contact irritants (e.g., wool, hairy pets, cleansers, fiberglass)

- Topical antipruritics may offer short-term relief Camphor/menthol preparations (Sarna lotion ${ }^{\star}$ ) Crotamiton $\left(\text { Eurax }^{\dagger}\right)^{48,49}$

Phenol (0.5\%-2.0\%)—do not use during pregnancy or in infants

Pramoxine HCI $\left(\operatorname{Prax}^{\ddagger}\right)^{50}$

Capsaicin cream ${ }^{51}$ - especially for well-localized itches Eutectic anesthetics ${ }^{52}$ - especially for well-localized itches Topical doxepin ${ }^{53}$-may be suitable for small areas of intact skin

- Systemic treatment

Antihistamines—for histamine-induced pruritus (e.g., urticaria)

Immunomodulators-for inflammation-induced pruritus -Topical: corticosteroids, ${ }^{54}$ macrolides ${ }^{55}$

-Systemic: corticosteroids, cyclosporine, others

Cholestyramine $^{56}$ : for renal failure, cholestasis, and polycythemia vera

Opiate antagonists: for atopic dermatitis, ${ }^{57}$ cholestasis $^{56,58}$ Oral cromolyn ${ }^{59}$ : for systemic mast cell disease $e^{60}$

Miscellaneous: gabapentin, thalidomide, oral primrose oil

- Physical modalities

Ultraviolet phototherapy and PUVA photochemotherapy

Thermal stimulation (heating or cooling the skin)

Acupuncture

TENS $^{61}$

Plasmapheresis $^{62}$

PUVA $=$ psoralen plus ultraviolet A therapy; TENS $=$ transcutaneous electrical nerve stimulation.

* Stiefel Laboratories, Inc., Coral Gables, FL.

${ }^{\dagger}$ Fujisawa Pharmaceuticals Co., Ltd., Osaka, Japan.

${ }^{\ddagger}$ Ferndale Laboratories, Inc., Ferndale, MI.

Antihistamine efficacy is assessed in terms of the agent's ability to inhibit the triple response of Lewis ${ }^{65}$ and to bind to $\mathrm{H}_{1}$ receptors in vitro. ${ }^{66}$ When antihistamines are administered to patients with urticaria, the itching often disappears before the clearance of the wheals and flares, as observed clinically by the author (VSB). Secondgeneration, nonsedating antihistamines seem to be more effective than sedating antihistamines because they are associated with better compliance.

\section{Comparative Studies with Newer and Older $\mathrm{H}_{\mathbf{1}}$ Antihistamines}

$\mathrm{H}_{1}$-receptor antagonists are widely used to treat allergic skin diseases characterized by pruritus, including urticaria and atopic dermatitis. These agents prevent pruritus 
by acting on the $\mathrm{H}_{1}$ receptors on the small, branching unmyelinated C-fibers in the skin. ${ }^{67}$ Thus, the distribution of the antihistamine into the skin to produce cutaneous $\mathrm{H}_{1}$ blockade would be important to its antipruritic effect.

Not surprisingly, comparative studies on antihistamine distribution in the skin are rare. In 1 such study, Simons et $\mathrm{al}^{68}$ in Canada compared the extent of fexofenadine and diphenhydramine distribution in the skin concomitantly with the $\mathrm{H}_{1}$-receptor antagonist activity. The results of this double-blind, prospective, randomized parallel-group study, comparing a newer nonsedating antihistamine with a classic sedating antihistamine, showed that fexofenadine given orally penetrated the skin (obtained by punch biopsy), and suppressed whealing, to a significantly greater extent than diphenhydramine given orally.

A review of controlled studies of various oral antihistamines in various types of urticarial disorders by Lee and Maibach ${ }^{69}$ summarized efficacy differences between the newer and older agents. This review found that the newer nonsedating antihistamines were as effective or more effective than the sedating antihistamines. ${ }^{69}$ Controlled, head-to-head comparisons of these agents would be definitive in identifying treatment for specific forms of urticaria. In any event, because the newer antihistamines do not cross the blood-brain barrier, in contrast to the older antihistamines, higher doses may be given if needed without sedation and psychomotor impairment. Accordingly, therapy with a newer nonsedating antihistamine presents a safe and effective alternative to use of an older sedating agent for pruritic skin disorders.

\section{Topical Corticosteroids}

Topical corticosteroids provide symptomatic relief of inflammation and/or pruritus associated with acute and chronic corticosteroid-responsive disorders. Zhai et $\mathrm{al}^{54}$ reported that the topical application of hydrocortisone $2.5 \%$ can significantly benefit histamine-induced pruritus. Systemic corticosteroids are indicated for the treatment of severe or incapacitating allergic disorders that fail to respond to conventional treatment.

Other therapeutic modalities appear in Table 3. Tacrolimus inhibits T-cell activation and has been effective in treating such $\mathrm{T}$-cell diseases as $\mathrm{AD},{ }^{70}$ psoriasis, and alopecia areata. Cholestyramine, opiate antagonists, and gabapentin are effective for certain pruritic conditions but not for histamine-induced pruritus. Aspirin was found more effective than chlorpheniramine for relief of itching in late pregnancy when no rash was present. ${ }^{71}$ Phototherapy (ultraviolet B and/or psoralen plus ultraviolet A), ${ }^{72}$ thermal stimulation (cooling or heating), transcutaneous electrical nerve stimulation, ${ }^{61}$ acupuncture, and plasmapheresis ${ }^{62}$ have all been used with success in selected cases of pruritus.

\section{CONCLUSION}

The sensation of itching, or pruritus, is the most common symptom of dermatologic conditions. The types and causes of pruritus are complex and varied. Although histamine is the primary mediator of itch in some allergic disorders, such as urticaria, there are multiple potential mediators of itch in both allergic and nonallergic disorders. The selection of therapy is facilitated when the etiology of an itching disorder is known. For example, histamine-induced itching generally responds to $\mathrm{H}_{1}$ antihistamines, whereas tacrolimus may be useful in such T-cell diseases as $\mathrm{AD}$. The challenge is to identify the cause of the symptom and to select the treatment that fits that mechanism.

\section{REFERENCES}

1. Savin JA. How should we define itching? J Am Acad Dermatol. 1998;38:268-269.

2. Verbov J. No laughing matter. Br J Dermatol. 1998;38:300.

3. Armstrong CA, Scholzen T, Olerud JE, et al. Neurobiology of the skin. In: Freeberg IM, Eisen AZ, Fitzpatrick TB (Eds), Fitzpatrick's Dermatology in General Medicine, 5th edition, vol. 1. New York: McGraw-Hill, 1999:321-326.

4. Denman ST. A review of pruritus. J Am Acad Dermatol. 1986;14:375-392.

5. Torebjork HE, Ochoa JL. Pain and itch from C fiber stimulation [abstract]. Soc Neurosci Abstr. 1981;7:228.

6. Melzack RH, Schecter B. Itch and vibration. Science. 1965; 147:1047-1048.

7. Melzack RH, Wall PD. Pain mechanisms: a new theory. Science. 1965;150:971-979.

8. Heyer G, Hornstein OP, Handwerker HO. Skin reactions and itch sensation induced by epicutaneous histamine application in atopic dermatitis and controls. $J$ Invest Dermatol. 1989;93:492-496.

9. Davies MG, Greaves MW. Sensory responses of human skin to synthetic histamine analogues and histamine. $\mathrm{Br} \mathrm{J}$ Clin Pharmacol. 1980;9:461-465.

10. Simone DA, Alreja M, LaMotte RH. Psychophysical studies of the itch sensation and itchy skin ("alloknesis") produced by intracutaneous injection of histamine. Somatosens Mot Res. 1991;8:271-279.

11. Hagermark O. Peripheral and central mediators of itch. Skin Pharmacol. 1992;5:1-8.

12. Greaves MW, McDonald-Gobson W. Itch: the role of prostaglandins. BMJ. 1973;3:608-609.

13. Hagermark $O$, Strandberg K. Pruritogenic activity of prostaglandin E2. Acta Derm Venereol. 1977;57:37-43.

14. Monash S, Woessner J. Pruritus and proteolytic enzymes. Arch Dermatol. 1958;78:214-217.

15. Lerner EA. Chemical mediators of itching. In: Bernhardt JD, ed. Itch: Mechanisms and Management of Pruritus. New York: McGraw-Hill, 1994:27-36.

16. Darsow U, Scharein E, Bromm B, Ring J. Skin testing of the pruritogenic activity of histamine and cytokines (interleukin-2 and tumour necrosis factor-alpha) at the dermal-epidermal junction. Br J Dermatol. 1997;137:415-417.

17. Soter N, Lewis R, Corey E, et al. Local effects of synthetic leukotrienes (LTC4, LTE4, LTD4, and LTB4) in human skin. J Invest Dermatol. 1983;80:115-119. 
18. Willemson MA, Lutt MA, Sterijlen PM, et al. Clinical and biochemical effects of zileuton in patients with the SjögrenLarsson syndrome. Eur J Pediatr. 2001;160:711-717.

19. Gorski P, Ulinski S. Effect of occupational exposure to opiates on the respiratory system. Int J Occup Med Environ Health. 1996;9:245-253.

20. Barke KE, Hough LB. Opiates, mast cells and histamine release. Life Sci. 1993;53:1391-1399.

21. Stellato C, Cirillo R, dePaulis A, et al. Human mast cell releasability. IX. Heterogeneity of the effects of opioids on mediator release. Anesthesiology. 1993;53:932-940.

22. Fjellner B, Hagermark O. Potentiation of histamine-induced itch and flare responses in human skin by the enkephalin analogue FK 33-824, beta endorphin and morphine. Arch Dermatol Res. 1982;274:29-37.

23. Charlesworth EN. Practical approaches to the treatment of atopic dermatitis. Allergy Proc. 1994;15:269-274.

24. Hanifin JM, Rajka G. Diagnostic features of atopic dermatitis. Acta Derm Venereol (Stockh). 1980;92:44-49.

25. Koblenzer CS. Itching and the atopic skin. J Allergy Clin Immunol. 1999;104:S109-S113.

26. Leung DY, Hanifin JM, Charlesworth EN, et al. Disease management of atopic dermatitis: a practice parameter. Ann Allergy Asthma Immunol. 1997;79:197-211.

27. Charlesworth EN. The spectrum of urticaria. All that urticates may not be urticaria. Immunol Allergy Clin North Am. 1995;15:641-657.

28. Grattan $\mathrm{CEH}$, Charlesworth EN. Urticaria. In: Holgate ST, Church MK, Lichtenstein LM, eds. Allergy, 2nd ed. St. Louis: Mosby, 2001:93-104.

29. Kaplan AP, Gray L, Shaff RE, Horakova Z, Beaven MA. In vivo studies of mediator release in cold urticaria and cholinergic urticaria. J Allergy Clin Immunol. 1975;55:394-402.

30. Kaplan AP, Horakova Z, Katz S. Assessment of tissue fluid histamine levels in patients with urticaria. $J$ Allergy Clin Immunol. 1978;61:350-354.

31. Hide M, Francis DM, Grattan CEH, et al. The pathogenesis of chronic idiopathic urticaria: new evidence suggests an autoimmune basis and implications for treatment. Clin Exp Allergy. 1994;24:624-627.

32. Zavadak D, Tharp MD. Chronic urticaria as a manifestation of the late phase reaction. Immunol Allergy Clin North Am. 1995;15:745-759.

33. Charlesworth EN. Urticaria and angioedema: a clinical spectrum. Ann Allergy Asthma Immunol. 1996;76:484-496.

34. Charlesworth EN, Kagey-Sobotka A, Norman PS, et al. Effect of cetirizine on mast cell mediator release and cellular traffic during the cutaneous late-phase reaction. $J$ Allergy Clin Immunol. 1989;83:905-912.

35. Charlesworth EN, Massey WA, Kagey-Sobotka A, Norman PS, Lichtenstein LM. Effect of $\mathrm{H}_{1}$ receptor blockade on the early and late response to cutaneous allergen challenge. J Pharmacol Exp Ther. 1992;262:964-970.

36. Massey WA, Charlesworth EN, Friedhoff L, et al. Cutaneous IgE-mediated inflammatory lesion size is inhibited by an $\mathrm{H}_{1}$ antagonist (Terfenadine) while mediator release is unaffected in vivo and in vitro. Clin Exp Allergy. 1993;23:399405.

37. Venzor J, Baer SC, Huston DP. Urticarial vasculitis. Immunol Allergy Clin North Am. 1995;15:761-774.

38. Metcalfe DD. Conclusions. Clinical advances in mastocytosis: a roundtable discussion; June 15, 1990; Southampton, Bermuda. J Invest Dermatol. 1991;96:55S-59S.

39. Lauterburg BH, Taswell HF, Pineda AA, Dickson ER, Burgstaler EA, Carolson GL. Treatment of pruritus of cholestasis by plasma perfusion through USP-charcoal-coated glass beads. Lancet. 1980;2:53-55.

40. Neiman RS, Bischel MD, Lukes RJ. Uraemia and mast-cell proliferation [letter]. Lancet. 1972;i:959.

41. Francos GC, Kauh YC, Gittlen SD, et al. Elevated plasma histamine in chronic uremia. Effects of ketotifen on pruritus. Int J Dermatol. 1991;30:884-889.

42. Ghent CN, Bloomer JR, Klatskin G. Elevations in skin tissue levels of bile acids in human cholestasis: relation to serum levels and to pruritus. Gastroenterology. 1977;73:11251130.

43. Jones EA, Bergasa NV. Pruritus of cholestasis and the opioid system. JAMA. 1992;268:3359-3362.

44. Metze D, Reimann S, Beissert S, Luger T. Efficacy and safety of naltrexone, an oral opiate receptor antagonist, in the treatment of pruritus in internal and dermatological diseases. J Am Acad Dermatol. 1999;41:533-539.

45. Fjellner B, Hagermark O. Pruritus in polycythaemia vera: treatment with aspirin and possibility of platelet involvement. Acta Dermatol Venereol. 1979;59:505-512.

46. McGrath JA, Greaves MW. Aquagenic pruritus and the myelodysplastic syndrome. Br J Dermatol. 1990;123:414415.

47. Barghuthy FS, Kumar V, Valeski E, Beutner EH, Chorzelski TP. Identification of IgA subclasses in skin of dermatitis herpetiformis patients. Int Arch Allergy Appl Immunol. 1988; 85:268-271.

48. Smith EB, King CA, Baker MD. Crotamiton lotion in pruritus. Int J Dermatol. 1984;23:684-685.

49. Holme SA, Mills CM. Crotamin and narrow-band UVB phototherapy: novel approaches to alleviate pruritus of breast carcinoma skin infiltration. J Pain Symptom Manage. 2001;22:803-805.

50. Yosipovitch G, Maibach HI. Effect of pramoxine on experimentally induced pruritus in human. Am Acad Dermatol. 1997;37:278-280.

51. Weisshaar E, Heyer G, Forster C, et al. Effect of topical capsaicin on the cutaneous reactions and itching to histamine in atopic eczema compared to healthy skin. Arch Dermatol Res. 1998;290:306-311.

52. Kopecky EA, Jacobson S, Bach MB, et al. Safety and pharmacokinetics of EMLA in the treatment of postburn pruritus in pediatric patients: a pilot study. $J$ Burn Care Rehabil. 2001;22:235-242.

53. Smith PF, Corelli RL. Doxepin in the management of pruritus associated with allergic cutaneous reactions. Ann Pharmacother. 1997;31:633-635.

54. Zhai H, Frisch S, Pelosi A, et al. Antipruritic and thermal sensation effects of hydrocortisone creams in human skin. Skin Pharmacol Appl Skin Physiol. 2000;13:352-357.

55. Choi CJ, Nghiem P. Tacrolimus ointment in the treatment of chronic cutaneous graft-vs-host disease: a case series of 18 patients. Arch Dermatol. 2001;137:1202-1206.

56. Rust C, Sauter GH, Oswald M, et al. Effect of cholestyramine on bile acid pattern and synthesis during administration of ursodeoxycholic acid in man. Eur $J$ Clin Invest. 2000;30:135-139.

57. Bergasa NV, Alling DW, Talbot TL, et al. Relief from the intractable pruritus of chronic cholestasis associated with oral nalmefene therapy [abstract]. Hepatology. 1001;14: 154A.

58. Harrison PV. Nalmefene and pruritus [letter]. J Am Acad Dermatol. 1990;23:530. 
59. Paquette D, Rothe MJ. Unapproved dermatologic indications for $\mathrm{H}_{2}$ receptor antagonists, cromolyn, and ketotifen. Clin Dermatol. 2000;18:103-111.

60. Soter NA, Austen KF, Wasserman SI. Oral disodium cromoglycate in the treatment of systemic mastocytosis. N Engl J Med. 1979;301:465-469.

61. Monk BE. Transcutaneous electronic nerve stimulation in the treatment of generalized pruritus. Clin Exp Dermatol. 1993;18:67-68.

62. Gomez RL, Griffin JW, Squires JE. Prolonged relief of intractable pruritus in primary sclerosing cholangiitis by plasmapheresis. J Clin Gastroenterol. 1986;8:301-303.

63. Doenicke A, Moss J, Toledano A, Hoernecke R, Lorenz W, Ostwald P. Administration of $\mathrm{H}_{1}$ and $\mathrm{H}_{2}$ antagonists for chemoprophylaxis: a double-blind, placebo controlled study in healthy volunteers. J Clin Pharmacol. 1997;37:140-146.

64. Soter NA. Treatment of urticaria and angioedema: low sedating $\mathrm{H}_{1}$-type antihistamines. J Am Acad Dermatol. 1991; 24:1084-1087.

65. Naclerio RM, Baroody FM. $\mathrm{H}_{1}$-receptor antagonists: antiallergic effects in humans. In: Simons FER, ed. Histamine and $H_{1}$-Receptor Antagonists in Allergic Disease. New York: Marcel Dekker, 1996:145-174.
66. Church MK, Collinson AD, Okayama Y. $\mathrm{H}_{1}$-receptor antagonists: antiallergic effects in vitro. In: Simons FER, ed. Histamine and $\mathrm{H}_{1}$-Receptor Antagonists in Allergic Disease. New York: Marcel Dekker, 1996:117-144.

67. Church MK. Non- $\mathrm{H}_{1}$ receptor effects of antihistamines. Clin Exp Allergy. 1999;29(suppl 3):39-48.

68. Simons FER, Silver NA, Gu X. Skin concentrations of $\mathrm{H}_{1}$ receptor antagonists. J Allergy Clin Immunol. 2001;107: 526-530.

69. Lee EE, Maibach HI. Treatment of urticaria: an evidencebased evaluation of antihistamines. Am J Clin Dermatol. 2001;2:27-32.

70. Boguniewicz M, Fiedler VC, Raimer S, et al. A randomized, vehicle-controlled trial of tacrolimus ointment for treatment of atopic dermatitis in children. $J$ Allergy Clin Immunol. 1998;102:637-644.

71. Young GL, Jewell D. Antihistamine versus aspirin for itching in late pregnancy. Cochrane Database Syst Rev. 2000; CD000027.

72. Lebwohl M. Phototherapy of pruritus. In: Bernhard JD, ed. Itch: Mechanisms and Management of Pruritus. New York: McGraw-Hill, 1994:399-412. 